\title{
躍度最小モデルを用いた動作予測に基づく 人間一ロボット協調作業*
}

前田雄 ${ }^{* 1}$, 原崇之新井民夫*2

\section{Human-Robot Cooperative Manipulation with Motion Estimation Using Minimum-Jerk Model}

\author{
Yusuke MAEDA, Takayuki HARA and Tamio ARAI*3 \\ ${ }^{* 3}$ Department of Precision Engineering, School of Engineering, The University of Tokyo, \\ 7-3-1 Hongo, Bunkyo-ku, Tokyo, 113-8656 Japan
}

\begin{abstract}
In this paper, a control method of robots for human-robot cooperative manipulation is investigated. We propose estimating human motion using the minimum jerk model for smooth cooperation. Using nonlinear least-squares method, we identify two parameters of the minimum-jerk model in real-time. The estimated position of the human hand is used to determine the desired position of the end-effector of the manipulator in virtual compliance control. The motion estimation enables robots to coordinate actively even for unknown trajectories of handled objects that human partners intend. We implemented the proposed method on an industrial 6-degree-of-freedom manipulator with a force sensor. In experiments of cooperative manipulation of a rubber pipe, the motion estimation improved human feeling in coordination. The improvement was quantitatively evaluated from the viewpoint of "unnecessary energy transfer."
\end{abstract}

Key Words: Robot, Manipulator, Motion Control, Human-Robot Cooperation, Cooperative, Manipulation, Minimum-Jerk Model, Energy Transfer

\section{1.はじめに}

人間とロボットの協調は, 人の知能とロボットのパ ワーの組み合わせにより，多くの複雑な作業を実現す る可能性を持っている．人間とロボットによる協調物 体操作（図 1）はその1つの典型例であり，近年研究 が活発に進められている(1)(9).

人間とロボットの協調物体操作では，ロボットを人 間にとって扱いやすくするために，人間の動作特性を 模做してロボットの制御を行うことが有効であると考

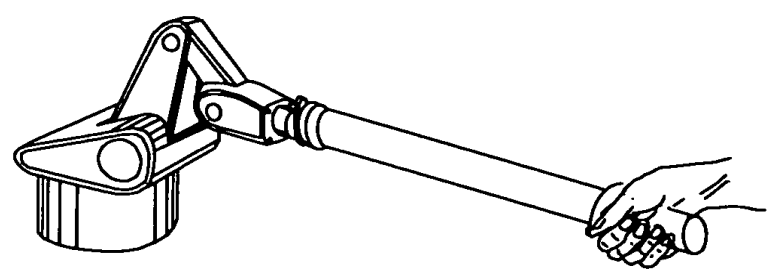

Fig. 1 Human-Robot Cooperative Manipulation

* 原稿受付 2001 年 12 月 6 日.

*1 東京大学大学院工学系研究科(《113-8656 東京都文京区本 班 7-3-1).

*2 正貝, 東京大学大学院工学系研究科.

E-mail : maeda@prince.pe.u-tokyo.ac.jp
えられる. Ikeura ら (1)や林原ら $^{(8)}$ は,人間同士の協調物 体操作からインピーダンス制御のパラメータを決定し, ロボット制御に適用した。しかしこれらの手法はバネ 係数をゼロとしているため, 物体操作方向に対しては, ロボットは反力を発生しながら受動的に追従すること になる，Rahman らは，対象物の基準位置を固定した 上でバネ係数を可変に制御することで，より積極的に ロボットを動かす手法を示している(4)が，インピーダ ンスパラメータの時間変化を事前に与える必要がある ため，特定の軌道にしか有効でない。したがって，ど のように対象物を動かすべきか事前に分かっている場 合にしか適用できないという難点がある.

Rahman $5^{(4)}$ ，Tsumugiwa $ら^{(9)}$ は，人間とロボットの 間の協調物体操作において，人間にとって扱いやすい 特性をロボットに持たせた結果として, 対象物の搬送 軌道が躍度最小軌道 ${ }^{(10)}$ に近いものになったと報告して いる.これは，人間が物を動かす際の自然な動きのモ デルが躍度最小軌道であることを考えると，妥当な結 果であると言える。そこで，ここでは逆に，躍度最小 モデルを利用して人間の動きをリアルタイムに予測す ることによりロボットの制御を行う手法を提案する. これにより，未知の搬送軌道に対しても，ロボットを 
積極的に人間に協調させることを目指す．

\section{2. 仮想コンプライアンス制御}

ここでは協調作業の奏現に，通常の位置制御マニピ ュレータを使用することを想定する。ロボットの動作 に柔らかさを持たせるため, カセンサを利用した仮想 コンプライアンス制御(11)を行う。ただし，本論文では， 並進の 3 自由度に関してのみコンプライアンスを与え ることとする。

離散時間系の仮想コンプライアンス制御では，ロボ ットの動作は以下の式より決定できる.

$$
\begin{aligned}
& M \frac{\left(x_{n+1}-x_{n}\right)-\left(x_{n}-x_{n-1}\right)}{(\Delta t)^{2}} \\
= & f_{n}-D \frac{x_{n}-x_{n-1}}{\Delta t}-K\left(x_{n}-\hat{x}_{n}\right)
\end{aligned}
$$

ただし, $\boldsymbol{M}, \boldsymbol{D}, \boldsymbol{K}$ は仮想質量・粘性・バネ係数であり， $\boldsymbol{x}_{n}$ と $\hat{\boldsymbol{x}}_{n}$ はそれぞれ第 $n$ サンプリング時間での手先位 置の実際値および目標值である。また， $f_{n}$ は力セン サによって測定される外力， $\Delta t$ がサンプリング周期 である。

仮想コンプライアンス制御では， $\boldsymbol{K} \equiv \boldsymbol{O}$ （もしく は等価的に $\hat{\boldsymbol{x}}_{n} \equiv \boldsymbol{x}_{n}$ ) の「直接教示モード」を用いて， ロボットを外力によって受動的に動かすことも可能で あるが, 本論文では，人間の動作の予測に基づいて

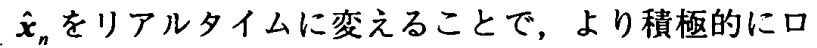
ボットを動作させることを考える.

\section{3.人間の動作予測}

躍度最小モデル(10)では，人間の腕の動作は，以下の ような評価関数を最小化するような軌道として定式化 される。

$$
J=\int_{0}^{t}\|\ddot{x}\|^{2} d t
$$

ただし， $t_{f}$ は動作に要する時間である。 $\dot{\boldsymbol{x}}(0)=\dot{\boldsymbol{x}}\left(t_{f}\right)=0$ および $\ddot{x}(0)=\ddot{x}\left(t_{f}\right)=0$ の場合は, 躍 度最小軌道は以下のような 5 次関数の形で書くことが できる。

$$
\begin{aligned}
\boldsymbol{x} & =\boldsymbol{g}\left(t ; t_{f}, x_{f}\right) \\
& =x_{0}+\left(15 \tau^{4}-6 \tau^{5}-10 \tau^{3}\right)\left(x_{0}-x_{f}\right)
\end{aligned}
$$

ここで $x_{0}$ と $x_{f}$ はそれぞれ手先のスタート位置および コール位置である. また， $\tau=t / t$ ，とする $(0 \leq \tau \leq 1)$.

躍度最小モデルは人間ーロボット協調作業にも適用 可能である(4)ことから，ここではこのモデルを使って， 人間の動作の予測を行うことを考える. 協調物体操作 においては，人間の手先とロボットの手先の間の位置
関係がほほ一定なので，以降ではロボットの手先軌道 に対して躍度最小モデルを用いた予測を行う．式(3.2) の未知パラメー夕は $t_{f}$ と $x_{f}$ であるので,これらが推 定できれば良い，本論文では，下記の評価関数を最小 にするように，重みつき非線形最小二乗法を用いて決 定する.

$$
\sum_{i=0}^{n}\left(\alpha^{n-i}\left\|\boldsymbol{x}_{i}-\boldsymbol{g}\left(i \Delta t ; t_{f}, \boldsymbol{x}_{f}\right)\right\|\right)^{2}
$$

ただし， $\alpha$ は忘却係数 $(0<\alpha<1)$ である.非線形最小 二乗法として Levenberg-Marquardt 法(12)を利用し， $t_{f}$ と $x_{f}$ を推定する. そして, 次のサンプリング時間で の仮想コンプライアンス制御の目標位置を，予測結果 から

$$
\hat{\boldsymbol{x}}_{n+1}=\boldsymbol{g}\left((n+1) \Delta t ; t_{f}, \boldsymbol{x}_{f}\right)
$$

と決める。このような動作予測に基づく制御により， 「直接教示モード」より積極的にロボットを動かすこ とが可能となる．動作予測は毎サンプリング時間で行 い，目標位置はりアルタイムに決定される。

ただし，物体操作の最初の段階では，対象物位置の データが少ないため，それを用いたパラメー夕推定は 不安定になってしまう．また，協調動作の最終段階で は，動作予測に基づく制御が人間の意図どおりの位置 決めを妨げる危険がある，そこで，仮想バネ係数 $\boldsymbol{K}$ を次式のように台形状に変化させることによって，動 作の初期段階および最終段階では直接教示モードで動 かす.

$$
a=\left\{\begin{array}{cc}
\multicolumn{1}{c}{\boldsymbol{K}=a \boldsymbol{K}_{0}} \\
0 & (0 \leq \tau \leq p) \\
(\tau-p) /(q-p) & (p \leq \tau \leq q) \\
1 & (q \leq \tau \leq 1-q) \\
(1-p-\tau) /(q-p) & (1-q \leq \tau \leq 1-p) \\
0 & (1-p \leq \tau \leq 1)
\end{array}\right.
$$

$K_{0}, p, q$ はすべて定数である $(0 \leq p \leq q \leq 0.5)$. な お， $t_{f}$ は未知であるため，このバネ保数の制御も動 作予測に基づいて行われるということに注意されたい.

\section{4. 協調物体操作の実験}

$4 \cdot 1$ 実験システム 人間ーロボット間の協調物 体操作のための実験システムを図 2 に示す，操作対象 物としては，長さ $500 \mathrm{~mm} \cdot$ 質量 $1.6 \mathrm{~kg} \cdot$ 曲げ剛性約 $15 \mathrm{Nm}^{2}$ のゴムパイプを用いた。 一方の端を人間が，も う片方をロボットが把持することにより，協調してこ の物体を動かす。ロボットとしては，16ms 間隔での 位置制御が可能な 6 自由度マニピュレータを用いた。 また，仮想コンプライアンス制御のため，手先に6軸 
カセンサを設けた。カセンサの值は $2 \mathrm{~ms}$ 間隔で取得 できる.

また，人間が対象物に及ほす力のデータを計測する ために，人間が把持する側にも6 軸カセンサを設けて いる。ささらに，人間の動作軌跡を得るため， 2 台の CCD カメラを用いた三次元運動計測装置（応用計測 研究所製 VideoTracker G280）を利用している。この 運動計測䒧置では，人間の手先に取り付けられたマー カを観測し，DLT (Direct Linear Transformation) 法 ${ }^{(13)}$ 用いることにより，手先の座標を $16 \mathrm{~ms}$ 間隔で取得す ることができる。なお，これら人間側のセンサは実験 結果の解析のために用いるものであり，ロボットの制 御はあくまでロボット側のセンサのみに基づいて行わ れる.

$4 \cdot 2$ 協調物体操作 人間とロボットの間での協 調物体操作の実験を行った。ここでは単純化のため, 対象作業を 1 次元の水平な物体操作とする. 具体的に は，対象物の長手方向に垂直な水平方向（これを $x$ 軸 方向とする）の 1 次元に対してのみ動作予測に基づく 目標軌道を設定し，それ以外の方向には固定の目標位 置を与える。これによって, $x$ 軸方向以外には対象物 が動きにくくなり，搬送軌道が実質的に 1 次元の並進 運動と見なせるようになる．人間が对象物を初期位置 から（ロボットにとって未知の）目標位置まで, 任意 の（ロボットにとって未知の）速度で搬送し，それに したがってロボットが協調動作する.

比較のため, 動作予測に基づく我々の提案手法と, 動作予測を行わない（ $x$ 軸方向のみについての）直接 教示モードの場合での実験を行った。 なお, 仮想イン ピーダンスパラメータは, ロボット単体の安定条件内 で，試行錯誤により

$$
\begin{aligned}
& M=\left[\begin{array}{ccc}
1.79 & 0 & 0 \\
0 & 1.79 & 0 \\
0 & 0 & 1.79
\end{array}\right][\mathrm{kg}] \\
& D=\left[\begin{array}{ccc}
48.0 & 0 & 0 \\
0 & 48.0 & 0 \\
0 & 0 & 48.0
\end{array}\right][\mathrm{Ns} / \mathrm{m}] \\
& K_{0}=\left\{\begin{array}{l}
{\left[\begin{array}{ccc}
800 & 0 & 0 \\
0 & 800 & 0 \\
0 & 0 & 800
\end{array}\right][\mathrm{N} / \mathrm{m}]} \\
{\left[\begin{array}{ccc}
0 & 0 & 0 \\
0 & 800 & 0 \\
0 & 0 & 800
\end{array}\right][\mathrm{T} \text { 動予測ありの場合) }} \\
\\
\end{array}\right.
\end{aligned}
$$

と決定した。またその他のパラメータは

$$
\alpha=0.91, p=0.1, q=0.2, \Delta t=16[\mathrm{~ms}]
$$

とした.

図 3, 図 4 は，0.25m の協調般送を行った場合の典型 的な動作結果（ロボットおよび人間の手先の速度と位 直）である.これらを含め，以降のグラフはすべて， $x$ 軸方向の成分を表したものである，なお，それ以外 の速度成分は, ピーク值で比較して $x$ 軸方向の $1 / 10$ 以下と無視できるレベルである，動作予測がある場合 は，それに基づいてマニピュレータが積極的に動作す るため, 人間とロボットの速度プロファイルは躍度最 小軌道と似た釣鐘型になっている。この場合，人間は 対象物をほほ自分の意図どおりに動かすことができて おり, 操作が「軽い」と感じている.なお, ロボット の動作に若干の遅れが生じているのは，主に対象物の 弾性による。

一方, 動作予測を行わない場合，人間の速度プロフ

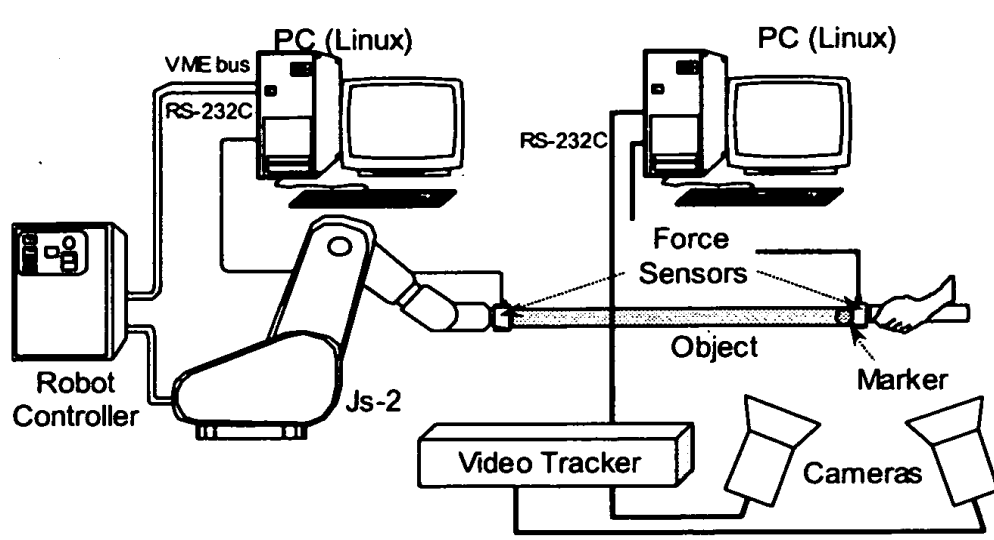

(a) Schematic View of Experimental Setup

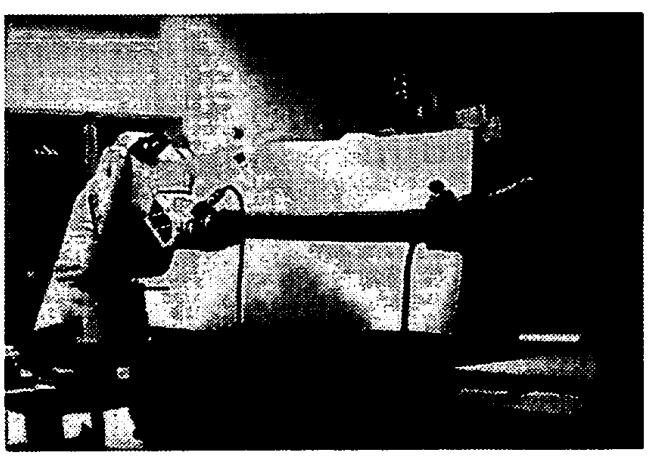

(b) A Scene of Cooperative Manipulation

Fig. 2 Experimental Setup for Cooperative Manipulation 


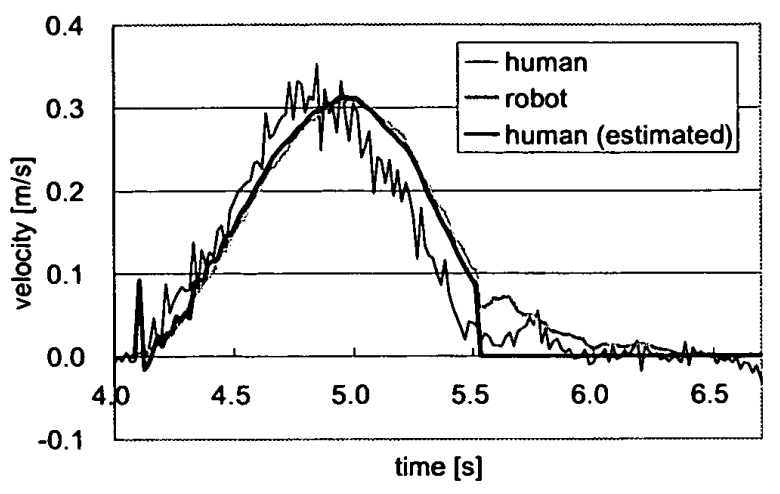

(a) with estimation

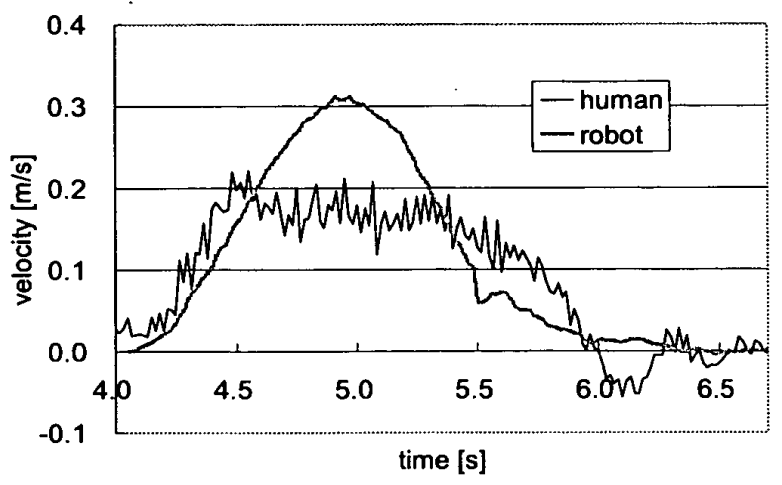

(b) without estimation

Fig. 3 Motion in Cooperative Manipulation (Velocity)

アイルは途中で頭打ちになっており, 躍度最小軌道と はかなり異なったものになっている。これは，ロボッ トの反応が悪いために，対象物を思い通りに動かせて いないことを意味しており，このとき操作者は，操作 が「重い」と感じた。

図 5 は，図 3 (a) の場合よりゆっくり対象物を動か した場合のグラフである．操作の速度が遅い場合は対 象物の弾性による影響が大きくなり，人間とロボット の速度プロファイルは少し異なったものになってしま うが，人間の動作は依然として躍度最小軌道に近い動 作を実現できている．今回は弾性体を対象物として実 験を行ったが，剛体の対象物を用いた場合は人間の力 がよりダイレクトにロボットに伝わるため，ロボット の動作遅れが小さくなることが期待される（ただし， 系全体の安定性のために, インピーダンスパラメータ の修正が必要になる可能性がある）。

なおこの実験において，式(3.3)の評価関数を最小化 するための Levenberg-Marquardt 法の反復回数を最大 6 回までとしたところ，実験に用いた PC (Pentium$200 \mathrm{MHz}$ ) では制御周期の $16 \mathrm{~ms}$ 以内で解を求めること ができた。

4.3 実験結果の定量的評価 ここでは，提案手 法による人間の操作感の改善を, 定量的に評価するこ

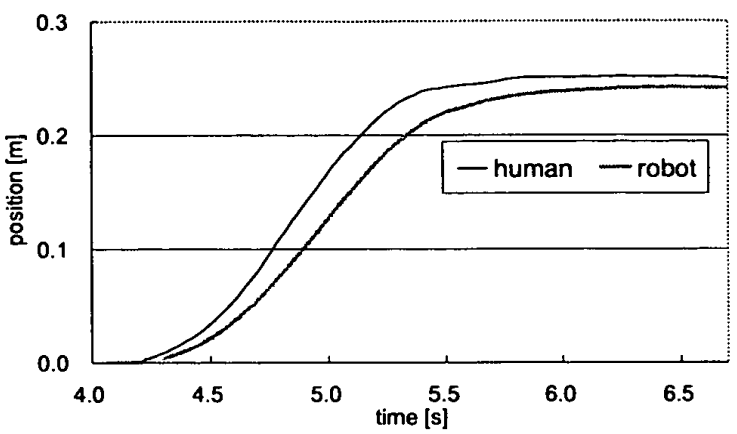

(a) with estimation

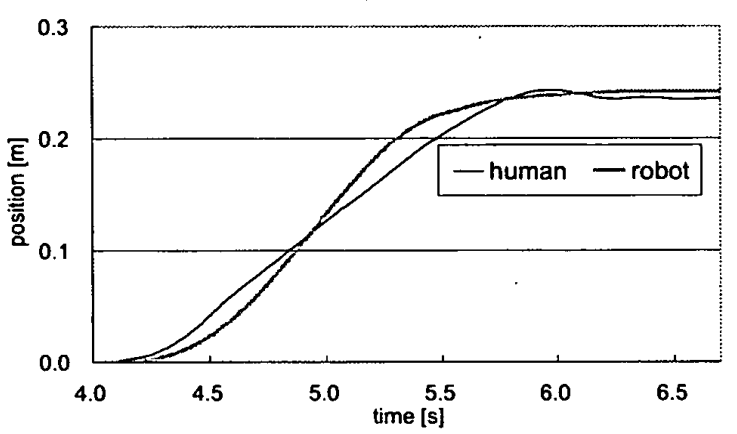

(b) without estimation

Fig: 4 Motion in Cooperative Manipulation (Position)

とを考える. 図 6 は協調搬送中のエネルギーの流れを 示したものである.これらのエネルギー授受量は，口 ボット側の手先位置および手先のカセンサの值，また 人間側の手先位置（運動計測装置で取得）および手先 の力センサの值からそれぞれ計算した。 人間から対象 物へのエネルギー授受量（ $E_{\mathrm{h}}$ とする），およびロボ

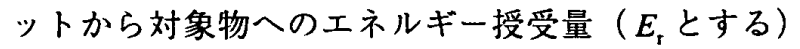
に対し，その和 $E_{\mathrm{h}}+E_{\mathrm{r}}$ が最終的に対象物を加減速す るために用いられたエネルギーとなる．操作の前半 (加速段階) では，エネルギーは人間から対象物およ びロボットへと流れる（図 7）。一方減速時には，人 間および对象物からロボットへとエネルギーが流れる. そこで, 本来の対象物の加減速に関係ないエネルギー の流れを「不要なエネルギーの授受」と考え, その量 を以下の式で定義する.

$$
E_{\text {unnecessary }}=\frac{1}{2} \int\left(\left|E_{\mathrm{h}}\right|+\left|E_{\mathrm{r}}\right|-\left|E_{\mathrm{h}}+E_{\mathrm{r}}\right|\right) d t
$$

$E_{\text {unnecessary }}$ は図 8 中の斑点で表された領域の面積に相 当する.なお，この斑点で表された部分とハッチング された部分の面積は等しいことに注意されたい。

「不要なエネルギーの授受量」は，人間とロボット の間での不要な相互作用の量を表しており,これを減 らすことは，物体の運搬方向の内力を隇らすことに対 応する。不要な相互作用量は, 部分系間の不適応を表 


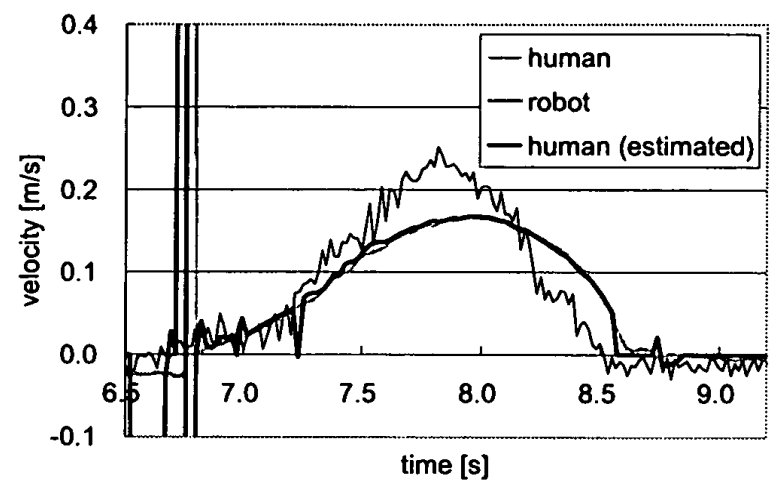

Fig. 5 Slower Manipulation with Estimation

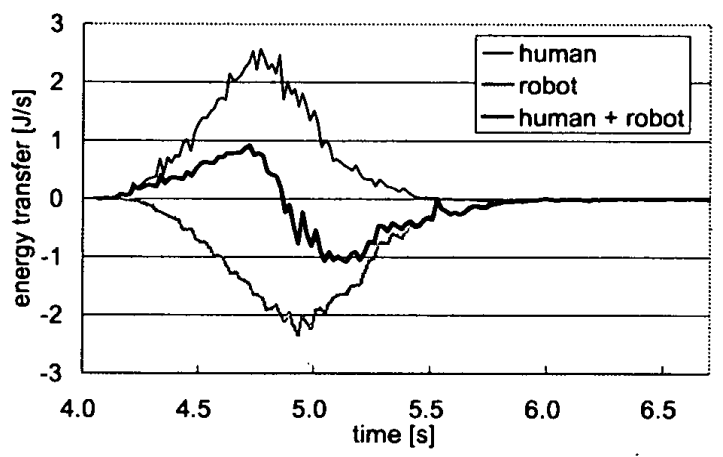

(a) with estimation

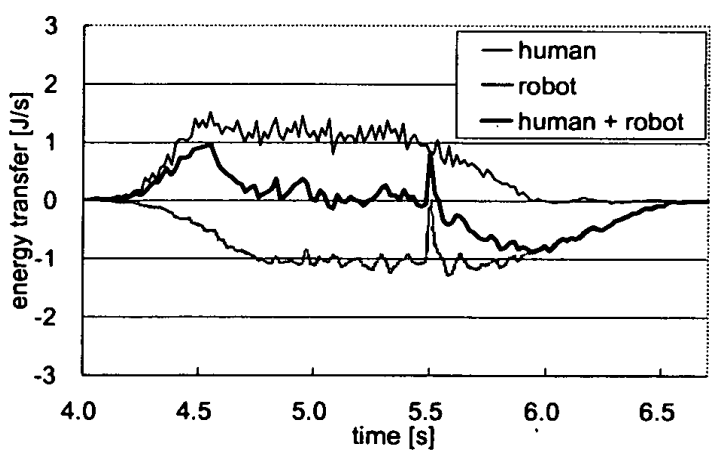

(b) without estimation

Fig. 6 Energy Transfer in Cooperative Manipulation

す指標としても利用されており年，これを協調作業の 評価に用いるのは多くの場合で妥当であると考えられ る.ただし，作業の目的や制約条件から，単純に「不 要なエネルギーの授受量」を隇らすことが不適切にな る場合もある，例えば，片側拘束によって対象物を把 持するような場合 ${ }^{(15)}$ (対象物の安定性を維持するため に，一定の内力をかけざるを得ない）や，ロボットの 直接教示における微小位置決め ${ }^{(16)}$ (人間の動きに逆ら う力を加えて位置決めをしやすくする）などである.

3 人の操作者について協調搬送の実験を行い，その ときの $E_{\text {unnecessary }}$ （5 回の平均）を表したのが（図 9） である．人間の動作予測を行うことで，不要なエネル

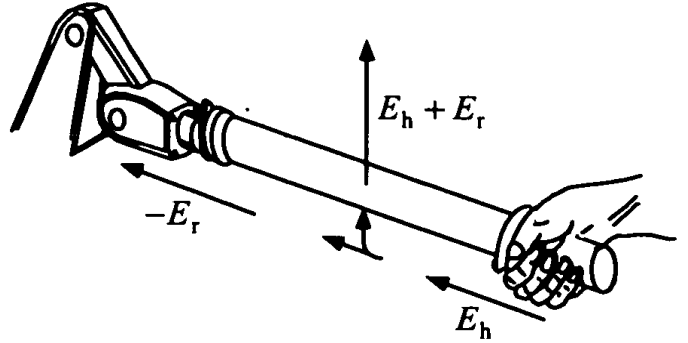

Fig. 7 Energy Transfer in Acceleration

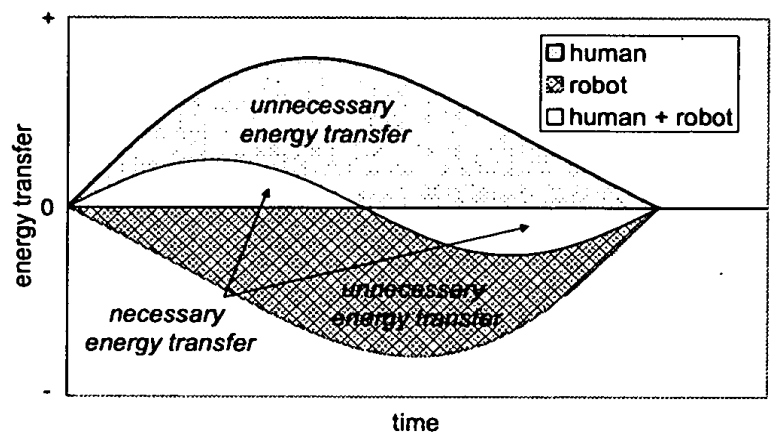

Fig. 8 Schematic View of Energy Transfer by Human and Robot

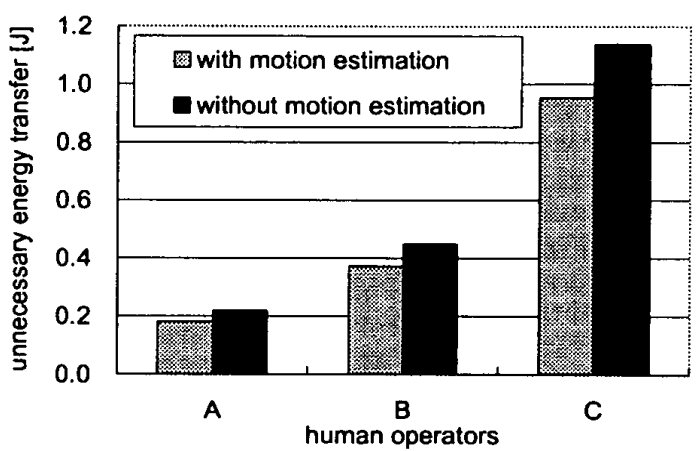

Fig. 9 Average Unnecessary Energy Transfer with/without Motion Estimation

ギー授受量が减少していることが見て取れる。なお， 操作者間の不要なエネルギー授受量の違いは，主に操 作のスピードの違いによるものである.

\section{5.おわりに}

本論文では，人間一ロボット協調作業において，人 間の動作のリアルタイム予測に基づくロボットの制御 手法を提案した．動作予測に躍度最小モデルを用いる ことで，未知の搬送軌道にも対応可能なロボットの制 御を実現した。

この制御手法を 6 自由度のマニピュレータ上に実装 して協調物体操作の実験を行った結果，人間の操作感 の改善が見られた，また，この改善は，「不要なエネ ルギー授受量」の隇少として, 定量的に評価できるこ とが分かった。

今後の課題としては, より複雑な物体操作への応用 
が挙げられる，躍度最小モデルでの予測誤差に応じて 仮想バネ定数の制御や過去の履歷の破棄を行うことで, ある程度複雑な搬送軌道にも対応が可能であると考え られる。

\section{謝 辞}

本研究は IMS/HMS (Holonic Manufacturing Systems) プロジェクトの一環として行われた.

\section{文献}

(1) R. Ikeura and H. Inooka: "Variable Impedance Control of a Robot for Cooperation with a Human," Proc. of 1995 IEEE Int. Conf. on Robotics and Automation, (1995), pp. 3097 3102.

(2) M. Al-Jarrah and Y. F. Zheng: "Arm-Manipulator Coordination for Load Sharing Using Variable Compliance Control," Proc. of 1997 IEEE lnt. Conf. on Robotics and Automation, (1997), pp. 895 901.

(3) J. Y. S. Luh and S. Hu: "Interactions and Motions in HumanRobot Coordination," Proc. of 1999 IEEE Int. Conf. on Robotics and Automation, (1999), pp: 3171 3176.

(4) M. M. Rahman et al.: "Investigating the Impedance Characteristic of Human Arm for Development of Robots to Cooperate with Human Operators," Proc. of 1999 IEEE Int. Conf. on Systems, Man, and Cybernetics, (1999), pp. 676 681.

(5) K. Kosuge et al.: "Mobile Robot Helper," Proc. of 2000 IEEE Int. Conf. on Robotics and Automation, (2000), pp. 583 588.

(6) 田塞, 荒井, 谷江, 林原: “人とロボットによる長尺物の協調 運搬（仮想非ホロノミック拘束による水平面内の制御手 法）," 日本機械学会論文集（C 編）, Vol. 66, No. 648, (2000), pp. 2677 2684.
(7) 山田, 大東, 酒井, 梅谷: “人間/ロボット共同搬送作業にお いて作業者の意向を反映させるためのヒューマンインタ ーフェイスの提案," 日本機械学会論文集 (C䋧), Vol. 67, No. 656, (2001), pp. 1069 1076.

（8）林原, 園田, 田窪, 荒井, 谷江: “人とロボットによる長尺物 の協調運搬（人との協調挙動に基づく鉛直平面内の制御 方法の検討），"日本機械学会論文集（C 編），Vol.67, No. 653, (2001), pp. 162 169.

(9) T. Tsumugiwa et al.: "Variable Impedance Control with Regard to Working Process for Man-Machine Cooperation-Work System," Proc. of 2001 IEEE/RSJ Int. Conf. on Intelligent Robots and Systems, (2001), pp. 1564 1569.

(10) T. Flash and N. Hogan: "The Coordination of Arm Movements: An Experimentally Confirmed Mathematical Model," J. of Neuroscience, Vol. 5, No. 7, (1985), pp. 1688 1703.

(11) 平林, 杉本, 荒井, 坂上: “多自由度ロボットの仮想コンブ ライアンス制御,”計測自動制御学会論文誌, Vol. 22, No. 3, (1986), pp. 343 348.

(12) W. H. Press et al.: "Numerical Recipes in C: The Art of Scientific Computing," Cambridge University Press, (1992).

(13) R. Shapiro: "Direct Linear Transformation Method for ThreeDimensional Cinematography," Research Quarterly, Vol. 49, No. 2, (1978), pp. 197 205.

（14）伊藤, 湯浅, 伊藤: “自律分散システムの適応理論,”計測 自動制御学会論文誌, Vol. 35, No. 5, (1999), pp. 684 692.

(15) 中村, 永井, 吉川: “複数のロボット機棈による協調的あや つ.クの力学,"日本ロボット学会誌, Vol. 4, No. 5, (1986), pp. 489 -498.

(16) 酒井: “ロボットの直接教示,” 日本ロボット学会誌, Vol. 13, No. 5, (1995), pp. 627 628. 